\title{
London kidney exchange in trouble
}

\section{British transplant physicians are in hot water for allegedly transplanting kidneys obtained by pur- chase. But buying kidneys may not always be wrong.}

IN the design of mammals, there is a useful measure of redundancy: some organs, the kidney conspicuously, appear in pairs, the redundancy being a safeguard against the stresses of long life: if one of a person's kidneys should fail, the other may be sufficient. Kidney transplants are a further safeguard. Most transplanted kidneys derive from cadavers, but because a person is not fatally or even severely damaged by the removal of one kidney, some are from living people, usually close relatives of the recipient. Nobody disputes the value of the procedure (which in Britain is believed to save $£ 50,000$ for each renal patient taken off dialysis machines). Worldwide, some tens of thousands of transplant operations are carried out each year, mostly in developed countries. (Just under 1,700 cadaver kidneys were transplanted last year in Britain alone.) The success rate is high (about 80 per cent one year after the operation, half as much ten years later).

Physiological redundancy has now also, it seems, stimulated a trade in human kidneys. For the past two weeks, London newspapers have been in pursuit of what they allege to be an international racket. There is proof that Turkish newspapers carry advertisements from would-be donors. It is alleged that a twolegged conspiracy based in Istanbul and London arranges for donors to be shipped to London for operations and, afterwards, to be paid. Some of the subsequent transplant operations are said to be carried out at London hospitals in the private sector. That makes the issue especially piquant on the eve of the publication of the government's proposals for the reorganization of its National Health Service, known to include suggestions that major hospitals in the public sector may opt for autonomy, selling medical services to the public and private sectors alike.

\section{Legislation}

If (as is probable) there is a trade in kidneys from living donors, there will also soon be vigorous demands in Britain that it should be made illegal. As things are, physicians are enjoined by professional guidelines not to take part in operations in which organs from living donors have been sold, although close relatives of a person with kidney failure may donate a kidney out of altruism. There is also a Council of Europe declaration that would outlaw the practice of transplanting organs obtained by purchase from living donors - if the declaration had legal force. But the question of whether there are circumstances in which a person may be allowed to sell a kidney of his or her own for cash is more complicated than it may seem.

Operationally, the underlying principles are clear, even simple. Physicians with patients in need of a kidney transplant naturally owe their first duty to them, but are not thereby ethically absolved from the responsibility of enquiring into the means by which kidneys for transplant are obtained. In part to protect the zealous transplant physicians from their proper zeal, it is standard practice when transplant organs are obtained from patients who have died in intensive care that an independent physician is responsible for deciding when the putative source is brain-dead. The same principles should apply with the transfer of organs from one living person to another. It should be for a physician independent of the intended recipient to shoulder ethical responsibility for the interests of the would-be donor.

Naturally, this second physician's chief responsibility (apart from seeking contra-indications to the proposed operation) must be to ensure that the intending donor is fully informed of the consequences, which are not as innocuous as the notion that one kidney is redundant would suggest. In normal people, kidney function becomes less efficient in middle life, and then progressively declines. However healthy a young donor may appear, losing a kidney must increase the risk of illness or even death in the second half of the normal lifespan. It is crucial to an understanding of what has been happening in London to know whether the Turkish donors so far tracked down were made fully aware of these extra risks. In principle, they might have been partly compensated by some form of health insurance, but there has so far been no suggestion of such arrangements. Indeed, the physicians most obviously concerned in the protection of the donors' interests have been singularly uncommunicative so far, yet they are those who shoulder the chief ethical responsibility.

With these provisos, there are two reasons why the practice of rewarding kidney donors even with sums of money large enough to provide an incentive should not be unthinkingly banned. First, there may be circumstances in which the balance of a potential donor's interests suggest that cash now justifies the risk of ill-health later. The simplest version of the hippocratic doctrine that no physician shall ever act so as to hazard a patient's health is easily challenged. What if the intending donor needs cash to care properly for a handicapped child, for example? Is the altruism that justifies the transfer of organs between relatives never transferrable to third parties? Even when there will be two beneficiaries (the recipient of the kidney and the object of the displaced altruism), not just one? It goes without saying that physicians will not win the freedom to use this or other possible shadings of hippocratic principles unless they are not merely willing, but eager, to describe and explain their conduct towards donors publicly - and to demonstrate that their own rewards are seemly. No doubt the medical profession's regulators will act with appropriate severity if these explanations do not emerge from the inquiries now under way in London.

The second reason why it is unwise to attempt to ban these practices is that the law is unlikely to be effective. Physicians where medical practice is relatively advanced inevitably attract patients from elsewhere. But the demand for kidney transplants is understandably so clamant that the trade (if there is one) will, if banned, shift to less squeamish places where standards of practice and (usually) ethics are high. Can that be to the greater good? Much the better way of blunting the problem is to ensure that the supply of organs for transplant is sufficient. In Britain, the National Transplantation Tissue Service, which operates within the public health service, is now able to meet only twothirds of the demand for kidneys. British private-sector medicine derives a few dozen kidneys a year from dwindling unmatched supplies from the United States, but otherwise relies on living donors. Yet the shortfall is not so great, and might be made good by better international arrangements for collecting, matching and delivering kidneys to where people need them. That, not legislation, is the way out of this dilemma. 